\title{
Immunohistochemical detection, regulation and antiproliferative function of G-protein-coupled receptor kinase 2 in thyroid carcinomas
}

\author{
Thierry Métayé ${ }^{1}$, Pierre Levillain ${ }^{2}$, Jean-Louis Kraimps ${ }^{3}$ and Rémy Perdrisot ${ }^{4}$ \\ ${ }^{1}$ Biophysics Laboratory, Departments of ${ }^{2}$ Pathology, ${ }^{3}$ Endocrine Surgery and ${ }^{4}$ Nuclear Medicine and Biophysics, CHU de Poitiers, \\ BP 577, 86021 Poitiers Cedex, France \\ (Correspondence should be addressed to T Métayé; Email: t.metaye@chu-poitiers.fr)
}

\begin{abstract}
TSH, via its G-protein-coupled receptor, activates cell growth of both benign and malignant thyroid tumors. G-proteincoupled receptors (GR) kinase 2 (GRK2) has been reported to regulate the TSH receptor but its role in cancer is unknown. To determine a possible function for GRK2 in the growth process of thyroid cancers, we analysed its expression in normal and tumoral thyroid tissues and studied thyroid cancer cell line proliferation after GRK2 overexpression. Thirty one thyroid tissues, including 16 non-medullary thyroid cancers and 15 adjacent normal tissues, were analysed by immunohistochemistry. Five paired tissues were also studied by western blotting for the GRK2 enzymatic activity. Immunohistochemical staining showed an increase in GRK2 in thyroid cancers including papillary, follicular, and anaplastic types, compared with their adjacent normal tissues. Immunoblot analysis and GRK2 enzymatic activity measurement confirmed
\end{abstract}

immunohistochemical study. TSH and TSH in association with insulin or IGF-I stimulated GRK2 protein accumulation in normal human thyroid cells in primary culture. The TSH effect on the GRK2 expression was mimicked by forskolin. After GRK2 overexpression in two poorly differentiated thyroid cell lines, all the clones showed a significant reduction in cell proliferation, ranging from 28 to $65 \%$ inhibition compared with vector alone after $96-\mathrm{h}$ culture. In conclusion, thyroid mitogenic factor-stimulated GRK2 accumulation may explain, in part, high GRK2 levels in differentiated carcinoma, because TSH, insulin, or IGF-I is known to be involved in the thyroid cancer progression. Surprisingly, instead of stimulating, GRK2 reduced cell proliferation revealing a new role for this kinase in the growth of thyroid cancers.

Journal of Endocrinology (2008) 198, 101-110

\section{Introduction}

G-protein-coupled receptor kinases (GRKs) are serine/ threonine protein kinases that control the desensitization process of G-protein-coupled receptor (GPCR) family (Pitcher et al. 1998). The molecular events underlying a desensitization mechanism start generally with agonistinduced receptor phosphorylation by a GRK. The phosphorylated GPCR possesses an increased affinity for a cytosolic protein of the arrestin family (arrestin 1-4). This complex (phosphorylated receptor/arrestin) prevents the further coupling of that receptor to its G-protein, reducing over time the capacity of second messenger synthesis. Resensitization is triggered by internalization of an uncoupled receptor to endosomal compartments, allowing its dephosphorylation by a protein phosphatase and recycling back to the cell surface or degradation (Moore et al. 2007). Based on sequence and functional similarities, the GRK family has been divided in three subfamilies: 1) the rhodopsin kinases (GRK1 and GRK7), 2) the $\beta$-adrenergic receptor kinases (GRK2 and GRK3), and 3) the GRK4, GRK5, and GRK6 subfamily (Ribas et al. 2007).
The thyrotropin (TSH) receptor belongs to the GPCR family and is a major determinant of thyroid function (Vassart \& Dumont 1992). Most of the TSH effects are mediated by cAMP via an adenylyl cyclase-activating $G \alpha$ protein, although at higher concentrations the TSH stimulates inositol 1,3,4-trisphosphate generation in human thyroid cells (Van Sande et al. 2006). A key role for GRK2, GRK5, and GRK6 was first demonstrated in the TSH receptor homologous desensitization using a rat thyroid cell line (FRTL-5; Iacovelli et al. 1996, 1999, Nagayama et al. 1996a). Subsequently, GRK3 was also shown to desensitize the TSH receptor in HEK 293 cells (Voigt et al. 2004). A predominant role for GRK5 (Metaye et al. 2002) and GRK3 (Voigt et al. 2004) has been suggested in differentiated thyroid carcinomas (DTC) and hyperfunctioning thyroid nodules respectively. Furthermore, these findings were reinforced by the detection of GRK proteins in human thyroid tissues (Voigt et al. 2004), with a major expression of GRK2 and GRK5 (Nagayama et al. 1996a, Metaye et al. 2002).

The mitogenic effect of cAMP on human thyrocytes has been well established in vitro and received convincing arguments in vivo (Leclere et al. 1984, Roger et al. 1988, 
Suarez et al. 1991, Parma et al. 1993, Russo et al. 1995). Indeed, the importance of TSH signaling in thyroid growth was demonstrated in DTC where the TSH suppression by thyroid hormone supplementation is used clinically to prevent the recurrence of thyroid cancer after surgery (Pujol et al. 1996). Therefore, understanding the TSH signaling regulation may help to better define new therapeutic targets in thyroid cancer progression. In DTC, we observed an increase in GRK2 activity, not confirmed at the protein level as measured on unpaired samples (Metaye et al. 2002). Thus, to bring a new insight into these findings, we decide to assess the GRK2 protein expression on paired samples using immunohistochemistry and to seek a role for GRK2 in thyroid cancers. We demonstrate that GRK2 protein is increased in non-medullary thyroid cancers including DTC and anaplastic carcinomas compared with their adjacent normal tissues. Moreover, the GRK2 protein expression is regulated by TSH, TSH+insulin or TSH+ insulin-like growth factor-I (IGF-I). Finally, we show that GRK2 overexpression attenuates the proliferative process of two different thyroid cancer cell lines in culture.

\section{Materials and Methods}

\section{Patient and sample characteristics}

For the measurement of GRK2 expression, 16 thyroid carcinomas (eight papillary, four follicular, and four anaplastic types) and their normal surrounding tissues (except one) were used. All the samples were obtained by surgery and embedded in paraffin for immunochemistry or stored in liquid nitrogen for GRK2 extraction. The tissue samples were randomly selected after histological examination by two pathologists independently and classified according to the World Health Organization recommendations (DeLellis et al. 2004). A consensus diagnosis was reached after discussion among the pathologists when a disagreement occurred. This study was approved by the Poitiers Hospital Ethics Committee. The mean age of patients was $49 \cdot 0$ years (S.D. 16.2) and $76 \cdot 2$ years (s.D. 9.1) for DTC and anaplastic carcinomas respectively. Cancers occurred in 5 males and 11 females. The mean tumor size of DTC was $2 \cdot 7 \mathrm{~cm}$ (s.D. $2 \cdot 6$ ). Six subjects exhibited positive lymph nodes and two had distant metastases preoperatively. Patients with thyroid cancers were biologically euthyroid and ${ }^{99 \mathrm{~m}} \mathrm{Tc}$ scintigraphies showed cold lesions. All the patients were without treatment before operation. Seven normal thyroid tissues (NTT) adjacent to benign nodules were used immediately after operation for primary cell culture.

\section{Immunohistochemistry}

Paraffined thyroid biopsy sections $(5 \mu \mathrm{m})$ were processed for immunocytochemistry using a commercially available kit (Dako REAL Detection system, Dako, Copenhagen,
Denmark). The sections were deparaffined, rehydrated, and heated to boiling point for $2 \mathrm{~min}$ in a pressure cooker containing citrate buffer at $\mathrm{pH} 6$. Thereafter, the sections were cooled down, rinsed in PBS, and incubated for $30 \mathrm{~min}$ at room temperature using rabbit polyclonal anti-GRK2 at a 1/400 dilution (C-15, Santa Cruz Biotechnology, Inc., Santa Cruz, CA, USA), and then they were rinsed in PBS and incubated with biotinylated anti-rabbit antibodies for $20 \mathrm{~min}$ at room temperature, rinsed again, and incubated with peroxidase-conjugated streptavidin. Peroxidase activity was revealed with $3,3^{\prime}$-diaminobenzidine in PBS. All the sections were counterstained with hematoxylin, examined under blind condition and photographed. The sections incubated without anti-GRK2 antibody were used as a negative control and a tissue clearly positive in a preliminary experiment was prepared subsequently as a positive control. The C-15 antibody was specific for GRK2 and there was no cross reaction with GRK5 by western blotting (not shown). GRK3 and GRK6 proteins were undetectable in thyroid extracts using antibodies from Santa Cruz Biotechnology (Metaye et al. 2002). For each case, the percentage of positive cells and intensity of the immunoreactivity were given for the tumorous zone, the surrounding and distant normal tissues. The intensity of staining of positive cells was measured using a scale from $(1+)$ to $(3+)$ by a pathologist; $(1+)$ represents weak staining, $(2+)$ moderate staining, and $(3+)$ strong staining.

\section{Sample preparation and GRK partial purification}

Human thyroid tissues were cut into small pieces with a razor blade and mechanically pulverized at $-180{ }^{\circ} \mathrm{C}$. The powders were then homogenized at $4{ }^{\circ} \mathrm{C}$ in thrice its volume of HEPES buffer $(20 \mathrm{mM}$ HEPES, $2 \mathrm{mM}$ EDTA, $250 \mathrm{mM} \mathrm{NaCl}, 1 \mathrm{mM}$ dithiothreitol, 0.02\% Triton X-100, $0.2 \mathrm{mM}$ phenylmethylsulfonyl fluoride, $20 \mu \mathrm{g} / \mathrm{ml}$ leupeptin, $5 \mu \mathrm{g} / \mathrm{ml}$ aprotinin, and $0.2 \mathrm{mg} / \mathrm{ml}$ benzamidine $(\mathrm{pH} 7 \cdot 2)$ ) using an Ultra-Turrax homogenizer (Janke and Kunkel, Staufen, Germany). The homogenates were incubated under agitation for $1 \mathrm{~h}$ at $4{ }^{\circ} \mathrm{C}$ and centrifuged at $140000 \mathrm{~g}$ to isolate cytosols. Aliquots of cytosols were stored at $-70{ }^{\circ} \mathrm{C}$ until they were used for GRK2 immunoblottings.

For measurements of the GRK2 enzymatic activity, the cytosols were further purified by cation exchange chromatography using SP-Sepharose (GE Healthcare Europe GmbH, Orsay, France), as described previously (Metaye et al. 2002), allowing to eliminate protein kinase $\mathrm{C}$ and thyroglobulin that interfere with phosphorylation and cellular protein assays respectively. The final extracts were stored at $-70{ }^{\circ} \mathrm{C}$ and used for phosphorylation assays.

Positive GRK2 controls were obtained from the cytosolic fraction of transfected COS-7 cells with expression vector containing GRK2 cDNA from human origin.

Protein concentrations were determined by the method of Bradford (1976) with a Bio-Rad protein assay reagent, using BSA as standard (Bio-Rad Labs). 


\section{Determination of $G R K 2$ protein expression}

The GRK2 protein expression was determined by electrophoresis and immunoblotting, as described previously (Metaye et al. 2002). SDS-PAGE was performed by the method of Laemmli (1970) with a 8.5\% separating gel. After electrophoresis, the proteins were electrotransfered to a polyvinylidene difluoride (PVDF) membrane. The PVDF membranes were incubated for $1 \mathrm{~h}$ at room temperature with anti-GRK2/3 monoclonal antibody clone C5/1·1 (Upstate Biotechnology, Lake Placid, NY, USA) using a $10^{-4}$ dilution. After several washings, the membranes were incubated for another hour in a $6.7 \times 10^{-5}$ dilution of peroxidaseconjugated second antibody. The immunoreactive bands were visualized with a commercial chemiluminescence system (ECL Plus, GE Healthcare Europe $\mathrm{GmbH}$ ). The films were optically scanned with model GS 300 densitometer (Hoefer Scientific, San Francisco, CA, USA). The peak areas were analyzed with a GS365W program, version 2.22 from Hoefer. Results from different blots were normalized using the same positive GRK2 control and expressed in percentage relative to NTT values. All the results were confirmed in at least two separate experiments.

\section{GRK2 enzymatic activity assay}

The GRK2 enzymatic activity was assayed using lightdependent phosphorylation of rhodopsin, as described previously (Gagon \& Kelly 1997, Metaye et al. 2002). Rod outer segment (ROS) membranes were prepared from dark-adapted bovine retinas and then treated with $5 \mathrm{M}$ urea to deactivate the endogenous rhodopsin kinase (Bennett \& Sitaramayya 1988). GRK2-dependent phosphorylation was measured by incubating $8 \mu \mathrm{g}$ of protein extracts with a reaction mixture containing $250 \mathrm{pmol}$ rhodopsin, $50 \mu \mathrm{M}\left[\gamma_{-}{ }^{32} \mathrm{P}\right] \mathrm{ATP}(2 \mathrm{Ci}$ ) mmol, GE Healthcare Europe $\mathrm{GmbH}), 20 \mathrm{mM}$ Tris- $\mathrm{HCl}$, $2 \mathrm{mM}$ EDTA, and $5 \mathrm{mM} \mathrm{MgCl}_{2}$ in the presence or absence of $2 \mu \mathrm{l}$ anti-GRK2 antibodies (clone C5/1·1, Upstate Biotechnology and C-15 from Santa Cruz Biotechnology, Inc.) at $\mathrm{pH} 7 \cdot 5$ in a final volume of $40 \mu \mathrm{l}$. The minimal epitope recognized by the clone $\mathrm{C} 5 / 1 \cdot 1$ is amino acids 483-485, whereas GRK2 antibody from Santa Cruz (C-15) was raised against a peptide corresponding to amino acids 675-689 mapping at the carboxy terminus of GRK2 from human origin. The reactions were carried out at $32{ }^{\circ} \mathrm{C}$ for $30 \mathrm{~min}$ in the presence or absence of light. The incubations were terminated by the addition of a sodium phosphate solution, followed by centrifugation. The ROS membrane pellets were resuspended in $20 \mu \mathrm{l}$ SDS sample buffer and electrophoresed on 10\% SDSpolyacrylamide gel. Rhodopsin bands were exposed for autoradiography and counted for ${ }^{32} \mathrm{P}$ radioactivity. Results, obtained by the difference between opsin phosphorylations in the presence and absence of light, were expressed as pmol of phosphate incorporated/min per $\mathrm{mg}$ protein. The GRK2 activity was the difference between data obtained in the absence and presence of antibodies. Anti-GRK2 antibodies brought more specificity to this assay because the GRK2 activity resulted from the activity really inhibited by antibodies and excluded other kinases able to phosphorylate rhodopsin. The enzymatic reaction was linear over 30-min period for an activity no greater than $50 \mathrm{fmol}$ phosphate incorporated/min. All the assays were performed with the same ROS membrane preparation and the results were confirmed in at least two separate experiments, tested in duplicate.

\section{Normal human thyroid cell culture}

Normal human thyroid tissues were obtained aseptically from patients who underwent thyroid surgery, usually for uninodular or multinodular goiter. Subsequent steps were performed as previously described by Roger et al. (1988). The isolated thyroid cells were cultured overnight in Dulbecco's modified Eagle's medium (DMEM)/Ham's F-12 $(1: 1)$ containing $5 \%$ foetal calf serum (FCS). Then, the cells were incubated for $24 \mathrm{~h}$ in serum-free medium containing $2.5 \mu \mathrm{g} / \mathrm{ml}$ human transferring, $40 \mu \mathrm{g} / \mathrm{ml}$ vitamin $\mathrm{C}$ and bovine TSH, insulin, IGF-I or forskolin at the indicated concentrations. A cytological examination with May-Grundwald Giemsa coloration indicated that cultures contained a minimum of $95 \%$ of living thyrocytes, less than $3 \%$ of interstitial cells and $1-2 \%$ of dead cells.

After incubation, the thyroid cells were detached from the culture dishes by treatment with trypsin, washed and homogenized with a Dounce homogenizer in HEPES buffer containing protease inhibitors. The homogenates were incubated under agitation for $30 \mathrm{~min}$ at $4{ }^{\circ} \mathrm{C}$ and centrifuged at $25000 \mathrm{~g}$. The supernatants were diluted in SDS sample buffer, heated at $95{ }^{\circ} \mathrm{C}$ for $5 \mathrm{~min}$ and used for GRK2 immunoblottings.

\section{Cell lines and stable transfection}

FTC-238 is a cell line (ECACC, Salisbury, UK) derived from a lung metastasis of a follicular thyroid carcinoma from a 42-yearold man (Demeure et al. 1992). BRA-2 is a thyroid cell line established in our laboratory in 1995 and derived from a lymph node metastasis of a papillary thyroid carcinoma from a 74-yearold woman. The BRA-2 cells have lost their ability to respond to TSH as measured by cAMP synthesis but are still stimulated by forskolin, a direct activator of adenylyl cyclase (Supplementary Figure 1, see Supplementary data in the online of version of the Journal of Endocrinology at http://joe.endocrinology-journals.org/content/vol198/issue1/). Thyroglobulin was not detectable in BRA-2 cytosol. The BRA-2 cells express the cytokeratin 7 protein but not the thyroid transcription factor 1 (TTF1) protein, suggesting an epithelial nature for these cells but also a partial dedifferentiated phenotype. Colony formation in soft agar was obtained with BRA-2 cells, demonstrating an anchorage-independent growth and a malignant disposition for these cells. Both cell lines (FTC-238 and BRA-2) were cultured in DMEM/Ham's F-12 (1:1) containing L-glutamine and supplemented with $10 \% \mathrm{FCS}$ at $37^{\circ} \mathrm{C}$ in a $5 \% \mathrm{CO}_{2}$ incubator. The cells were plated $24 \mathrm{~h}$ before transfection at $60 \%$ confluency 
on $35 \mathrm{~mm}$ in diameter plates. Stable transfections were performed using jetPEI reagent (Qbiogene, Montreal, Canada) for FTC-238 and Lipofectamine 2000 (Invitrogen) for BRA-2. The full-length cDNA of human GRK2 in pcDNA3.1 vector was obtained from GeneCopoeia (Germantown, MD, USA). The cell lines were transfected with $3 \mu \mathrm{g}$ GRK2 plasmid or with the same amount of the pcDNA3.1 empty vector in serumcontaining medium. The medium was aspired and transfected cells were then selected by inclusion of $400 \mu \mathrm{g} / \mathrm{ml} \mathrm{G} 418$ in the fresh medium $24 \mathrm{~h}$ after transfection. Colonies of resistant cells were visible after about 15 days. These colonies were individually harvested with trypsin using cloning rings, placed into multiwell cell culture dishes and expanded. Clones were always grown under antibiotic selective pressure. The expression level of GRK 2 in 12 different clones was determined by western blot analysis and cells expressing appropriated GRK2 levels were used.

\section{Cell growth measurement}

The cell lines were seeded in $75 \mathrm{~cm}^{2}$ culture flasks and allowed to grow in DMEM/Ham's F-12 (1:1) containing L-glutamine and supplemented with $10 \% \mathrm{FCS}$ at $37^{\circ} \mathrm{C}$ in a $5 \% \mathrm{CO}_{2}$ incubator for the indicated times. Cells were harvested with trypsin, washed with medium and exposed to trypan blue, which stains damaged cells only. The number of viable cells, those that excluded the dye, was counted using a Malassez cell.

\section{Statistical analysis}

Groups were compared in pairs using Student's $t$-test. A value of $P \leq 0.05$ was considered as a minimum level of significance.

\section{Results}

Immunohistochemical study of GRK2 expression in thyroid carcinomas

Sections from 16 thyroid carcinomas and 15 adjacent or distant NTT were subjected to immunohistochemical staining with antiserum to human GRK2, diluted at 1/400. The results are summarized in Table 1. GRK2 staining was obvious in neoplastic cells of papillary, follicular, and anaplastic types. Nearly, all malignant cells (80\% at least) from 12 out of the 16 samples were stained, whereas a few normal cells in the same section were weakly stained. Moreover, the staining intensity was stronger in carcinomas than in adjacent NTTexcept for two patients $(8$ and 10$)$ who had the same intensity in both tissues. No difference in percentage and intensity of NTTwas observed between the surrounding and distant normal tissue from the tumorous zone. The sections of GRK2-positive tissues resulted in positive cytoplasmic staining with no nucleus localization of the antibody (Fig. 1). Specimens exhibited a rather homogenous staining pattern. The follicular epithelial cells were principally stained but some rare stromal cells, vascular endothelial cells, and lymphocytic infiltrates did also react with the GRK2 antibody. The strong GRK2 immunostaining in all cancer tissues, including anaplastic type, hindered any discrimination or relationship with tumor aggressivity parameters.

Western blotting and GRK2 activity in paired samples of normal and cancerous thyroid tissues

To bring further arguments to immunohistochemical data with different methods, we performed GRK2 protein immunodetection by Western blotting and GRK2 activity

Table 1 Comparative immunohistochemical staining for G-protein-coupled receptor kinase 2 (GRK2) in thyroid carcinoma and paired normal samples

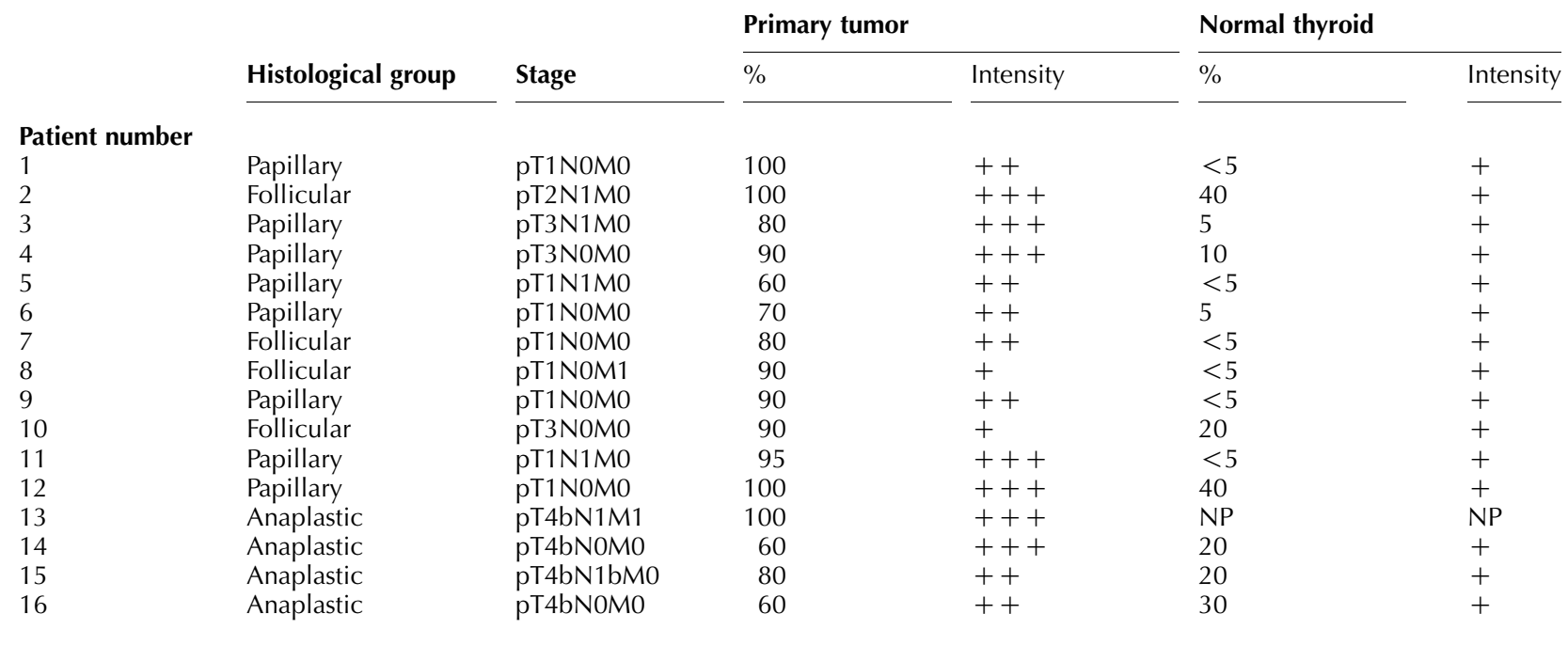

$\mathrm{NP}$, normal tissue was not present. 

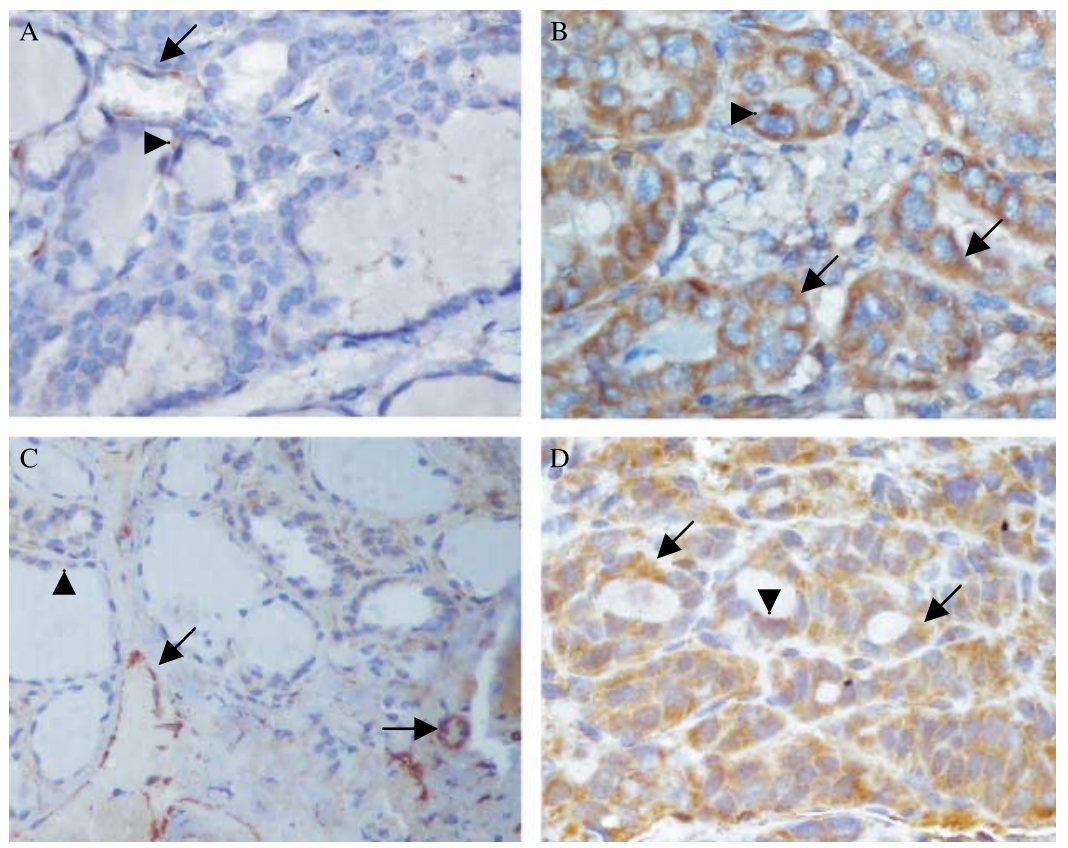

Figure 1 Immunohistochemical staining of GRK2 in two thyroid carcinomas (B and D) and their adjacent NTT (A and C). Representative sections from a papillary (B) and a follicular (D) carcinoma are shown (magnification $\times 1000$ ). Nuclei appear in blue and GRK2 in brown. A and C note the presence of GRK2 in thyrocytes (arrow heads) and in endothelial or stromal cells (arrows). B and D note the presence of GRK2 in the cytoplasm of cancerous cells (arrows) with sometimes a staining more pronounced in the apical part of the cell (arrow heads). The great majority of cells are strongly immunostained in cancers compared with normal tissues.

by a phosphorylation assay using rhodopsin as substrate. Five patients, already tested by immunohistochemistry, had sufficient tissue samples to perform GRK2 extraction in cancer tissue and paired NTT. A $79 \mathrm{kDa}$ immunoreactive band, comigrating with a recombinant GRK2 protein, was present in cytosols of NTT and thyroid carcinomas. Because GRK3 protein was not detected in NTT (Metaye et al. 2002), this suggest that GRK2 is the main $\beta$-adrenergic receptor kinase expressed in the human thyroid. Densitometric analysis of immunoblots (Fig. 2A) revealed a significant difference in relative expression of GRK2 protein between NTT $(8 \cdot 3 \pm$ $1 \cdot 7,14 \cdot 9 \pm 3 \cdot 0$, and $9 \cdot 6 \pm 0 \cdot 7 \%)$ and cancers $(100 \pm 5 \cdot 2$, $63 \cdot 4 \pm 5 \cdot 8$, and $36 \cdot 9 \pm 6 \cdot 5 \%$ respectively) in paired samples.

To measure the GRK2 activity, we used two anti-GRK2 antibodies, instead of heparin, to inhibit specifically rhodopsin phosphorylation by GRK2. Thus, the final results were the difference between total GRK activity minus activity obtained in the presence of anti-GRK2 antibodies (Supplementary Figure 2, see Supplementary data in the online of version of the Journal of Endocrinology at http:// joe.endocrinology-journals.org/content/vol198/issue1/). The whole protocol is extremely tissue consuming and only three paired samples of normal and cancerous thyroid tissues were available for treatment with $250 \mathrm{mM} \mathrm{NaCl}$ to extract GRKs. ROS were used in assay, resulting in phosphorylation of a $38 \mathrm{kDa}$ band that was consistent with the labeling of rhodopsin. The light-dependent phosphorylation of ROS by a recombinant GRK2 was completely inhibited by antiGRK2 antibodies, showing that these antibodies could be used in phosphorylation assay to assess GRK2 activity with accuracy (Supplementary Figure 2). GRK2 activities in cancer samples $(3 \cdot 46 \pm 0 \cdot 30,3 \cdot 01 \pm 0 \cdot 15$ and $6 \cdot 13 \pm$ $0.61 \mathrm{pmol} / \mathrm{min}$ per $\mathrm{mg}$ protein) were significantly increased compared with activities in adjacent NTT $(2 \cdot 24 \pm 0 \cdot 16$, $1 \cdot 03 \pm 0.08$ and $1 \cdot 73 \pm 0 \cdot 17 \mathrm{pmol} / \mathrm{min}$ per $\mathrm{mg}$ protein respectively; Fig. $2 \mathrm{~B}$ ).

Altogether, these results confirm the immunohistochemical study demonstrating with other methods an increased GRK2 expression in thyroid cancer compared with normal tissue. Moreover, we can point out some quantitative variations from one cancer or one NTT to another, that are not always revealed by immunohistochemistry.

\section{Regulation of GRK2 expression in human thyroid cell culture}

To study the influence of thyroid mitogenic factors in GRK2 expression, the role of TSH, insulin, and IGF-I was investigated in normal human thyroid cell culture. Furthermore, to discriminate cAMP effect in TSH action, forskolin was also tested. Cellular GRK2 from a 24-h cell culture was analyzed by 


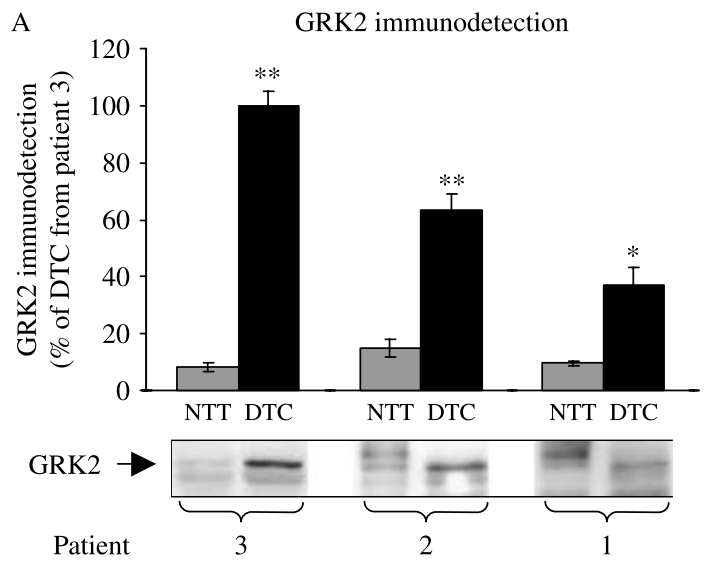

B

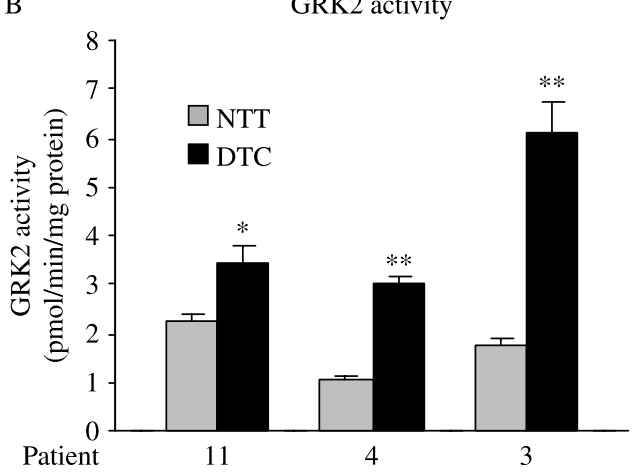

Figure 2 Assessment of GRK2 protein expression (A) and GRK2 activity (B) in thyroid carcinomas and their adjacent NTT. (A) The lower panel represent an autoradiography of a Western blot depicting GRK2 immunoreactivity in three patients. Twenty micrograms of cytosol proteins were analyzed for GRK2 expression and protein transfer was controlled by staining the PVDF membrane with Coomassie brilliant blue R-250. The upper panel is a densitometric analysis of the lower panel and the data are expressed in percent of DTC value from patient 3 . The migration of a recombinant GRK2 protein control is indicated by an arrow. The data represent the mean \pm s.D. confirmed in at least three separate experiments. (B) GRK2 activity was measured using partially purified samples of thyroid cancers and NTT, as described in Materials and Methods. Patient's numbers are the same as in Table 1. The data are means \pm range of duplicate determinations representative of two separate experiments. ${ }^{*} P<0 \cdot 01$; ${ }^{* *} P<0 \cdot 001$.

SDS-PAGE and immunoblotting (Fig. 3). A single band comigrating with a recombinant GRK2 was specifically detected by the anti-GRK2 antibody. A 24-h treatment of thyroid cells with TSH produced an increase $(1 \cdot 54$-fold) in GRK2 expression level when compared with the control, whereas insulin or IGF-I had little or no effect. Furthermore, when TSH was tested in the presence of insulin or IGF-I, GRK2 protein expression increased by $2 \cdot 0$ and 2.09 respectively, compared with the control. Forskolin mimicked TSH effect (Fig. 3) suggesting that the GRK2 increase was secondary to cAMP accumulation. These results were confirmed using thyroid cells from three different patients, at least. The ability of
$\mathrm{TSH}+\mathrm{TSH}+$ GRK2 Ctl TSH Ins IGF-I Ins IGF-I Ctl Fk
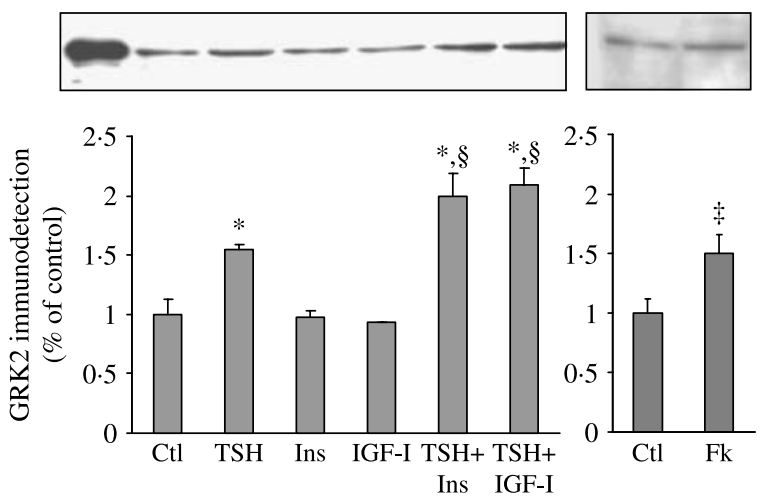

Figure 3 The regulation of GRK2 expression in normal human thyroid cell culture. Thyroid cells were cultured during $24 \mathrm{~h}$ in serum-free medium without (Ctl) or with $5 \mathrm{mU} / \mathrm{ml} \mathrm{TSH}, 5 \mu \mathrm{g} / \mathrm{ml}$ insulin (Ins), $100 \mathrm{ng} / \mathrm{ml} \mathrm{IGF-I,} \mathrm{TSH}(5 \mathrm{mU} / \mathrm{ml})$ plus insulin $(5 \mu \mathrm{g} / \mathrm{ml})$, TSH $(5 \mathrm{mU} / \mathrm{ml})$ plus IGF-I $(100 \mathrm{ng} / \mathrm{ml})$ and forskolin $(\mathrm{Fk}, 10 \mu \mathrm{M})$. Then, cellular GRK2 was extracted as described in Materials and Methods. Similar amounts of protein $(20 \mu \mathrm{g})$ were analyzed by Western blotting and protein transfer was controlled by staining the PVDF membrane with Coomassie brilliant blue R-250. In the upper panel, the GRK2 lane indicated the migration of a recombinant GRK2 protein. The lower panel is a densitometric analysis of the upper panel and the data are expressed in percent of $\mathrm{Ctl}$ value representing the mean \pm s.D. of four densitometric measurements. The results were confirmed in at least three separate experiments using different human thyroid cells. ${ }^{*} P<0.001$ compared with $\mathrm{Ctl}$; ${ }^{\ddagger} P<0.01$ compared with $\mathrm{Ctl}$, and ${ }^{\S} P<0.01$ compared with TSH.

TSH plus insulin or IGF-I to increase GRK2 even exceeded levels induced by the addition of each growth factor alone, eliciting a synergistic effect. TSH action on GRK2 expression was reproduced in an heterologous cell system, $\mathrm{CHO}$ cells transfected with TSH receptor cDNA and stimulated during 24 $\mathrm{h}$ in the presence of serum (data not shown).

\section{Effects of GRK2 overexpression on thyroid cancer cell proliferation}

The augmented level of GRK2 by thyroid mitogenic factors suggests a role for this kinase in the proliferative process. Therefore, to determine whether GRK2 have a key role in thyroid cancer progression, we studied the effect of GRK2 overexpression on the growth of two thyroid cancer cell lines (FTC-238 and BRA-2) cultured in medium containing 10\% serum. We generated different cellular clones by permanently transfecting cells with GRK2 cDNA and the empty vector pcDNA3.1 (vector) that was used as a control together with not transfected cells (NT). GRK2 overexpression resulted in 3.1- and 9.5-fold increase compared with NT in two different FTC-238 clones (Fig. 4Aa) and 21.7- and 38.9-fold increase compared with NT in two different BRA-2 clones (Fig. 4Ba). The growth rate was measured by counting cells using a hemacytometer. As shown in Fig. 4Ab and Bb, GRK2 expression limited the cell growth in all the clones tested in both cell lines, ranging from 28 to $65 \%$ inhibition compared 
A
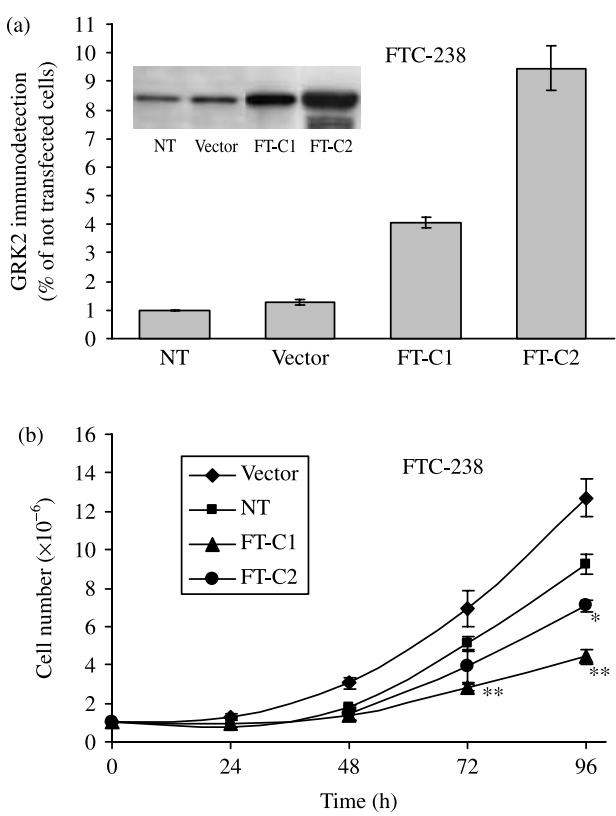

B
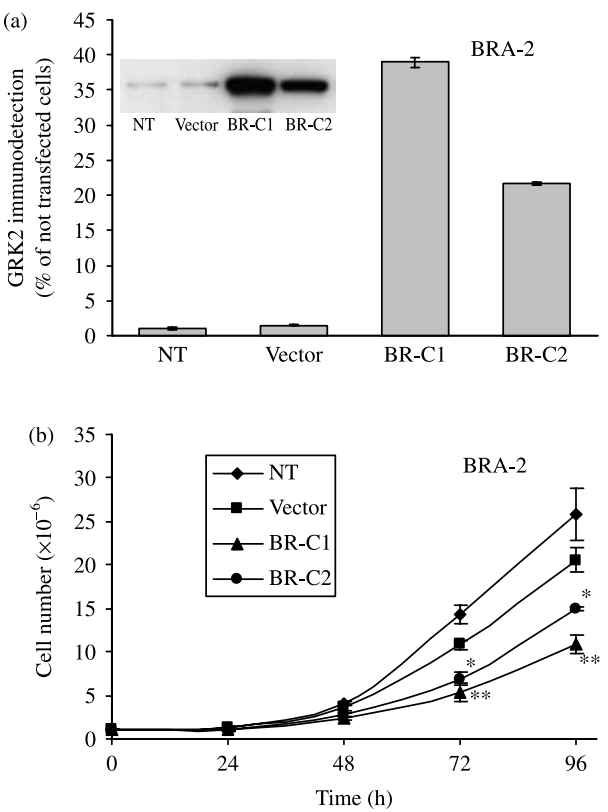

Figure 4 The effect of GRK2 expression on thyroid cancer cell growth in (A) FTC-238 and (B) BRA-2 cell lines. (a) Representative western blot and densitometric analysis, depicting GRK2 overexpression in FTC-238 or BRA-2 clones, permanently transfected with GRK2 CDNA (FT-C1, FT-C2 and BR-C1, BR-C2 respectively), empty vector (vector) or not transfected (NT). $20 \mu \mathrm{g}$ cytosol proteins were blotted and GRK2 immunoreactivity was detected as described in Materials and Methods. Data are representative of three independent experiments. (b) GRK2 overexpression attenuated serum-induced cell growth in FTC-238 and BRA-2 clones. Cells number was determined by counting viable cells four times using hemacytometer. Data are means \pm S.D. representative of two independent experiments. ${ }^{*} P<0.01$ compared with NT or vector; ** $P<0 \cdot 001$ compared with NT or vector.

with vector alone after 96 -h culture. The best results were for FT-C1 (FTC-238 clone 1) and BR-C1 (BRA-2 clone 1), with 65 and $47 \%$ reduction $(P<0 \cdot 001)$ in cell proliferation after 96 -h culture respectively.

\section{Discussion}

This study clearly demonstrates, using immunohistochemistry, an increase in GRK2 protein expression in non-medullary thyroid cancers compared with their adjacent normal tissues. Immunoblot analysis and GRK2 enzymatic activity measurement confirmed immunohistochemical study, revealing a greater GRK2 content in carcinomas, but also some variations in the levels of GRK2 expression more evident with these techniques than with immunohistochemistry. Paired thyroid samples are advisable to measure GRK2 expression because both normal and cancerous tissues from a single patient have the same TSH impregnation. This may explain that the present study is not in perfect agreement with our previous findings on unpaired samples where a slight increase in GRK2 in cancers had not reached a significant statistical level (Metaye et al. 2002).
Although GRK2 has been studied in hormone-dependent tumors of thyroid, ovary (King et al. 2003) and prostate (Prowatke et al. 2007), the regulation of its expression and its role in cancer progression remain unanswered. Our experiments on GRK2 regulation showed that thyroid mitogenic factors such as TSH or TSH in association with insulin or IGF-I increased GRK2 expression in primary culture of human thyrocytes. Therefore, our in vitro system mimics, in part, the in vivo phenotype of GRK2 expression in thyroid cancers. These results suggest that GRK2 synthesis might be induced by stimulation of receptors present in thyroid cancers as demonstrated for TSH, insulin, and IGF-I. The synergistic effect of TSH + insulin/IGF-I supports the stimulation of two different and convergent pathways, leading to GRK2 expression in thyroid cells. Effectively, in the present study, we show that cAMP-mediated forskolin stimulation increases GRK2 expression in human thyrocytes. This result demonstrates tissue specificity, because no forskolin effect was observed in cells with other origins, such as astrocytoma or aortic smooth muscle (Ramos-Ruiz et al. 2000). As the human TSH receptor stimulates Gas (Laugwitz et al. 1996), this suggests that TSH-stimulated cAMP accumulation might increase GRK2 synthesis. Furthermore, IGF-I by activating the PI3K/Akt pathway alters Mdm2-mediated GRK2 
ubiquitination and decreases GRK degradation (Salcedo et al. 2006). Overall, the hypothesis of TSH action on GRK synthesis stimulation and the effects of IGF-I or insulin (Shepherd 2005) on GRK2 stability might explain a synergistic interaction on GRK2 expression. However, the absence of TSH receptor in anaplastic carcinoma also suggests that the increased GRK2 protein is not necessarily linked to TSH receptor signaling in this thyroid cancer subtype. The regulation of GRK2 by $\mathrm{TSH}$ in normal thyrocytes agrees with the up-regulation of genes (phosphodiesterases and regulator of G-protein signaling 2, R GS2) involved in negative feedback of TSH-stimulated cAMP accumulation (Van Staveren et al. 2006) and with the decreased GRK2 expression observed in pathological thyroid tissues showing a reduced cAMP stimulation (Voigt et al. 2005). Furthermore, alterations of GRK2 expression have been reported in other systems with an increase observed in mitogen-activated lymphocytes (De Blasi et al. 1995), mouse heart following treatment with $\beta$-adrenergic agonist (Iaccarino et al. 1998), angiotensin II-stimulated cardiomyocytes (Theilade et al. 2002), and $\alpha_{1}$ adrenergic agonist-activated aorta smooth muscle cell line (Ramos-Ruiz et al. 2000); while proinflammatory cytokines, such as interleukin 1 , interleukin 6 , tumor necrosis factor- $\alpha$ or interferon- $\gamma$, decreased GRK2 expression in human mononuclear leucocytes (Lombardi et al. 1999) and in rat smooth muscle cell line (Ramos-Ruiz et al. 2000). In quite contrast with the up-regulation of GRK2, TSH reduced GRK5 protein level in rat thyroid cells (Nagayama et al. 1996b).

Early studies performed in thyroid cell cultures have shown that the mitogenic effect of TSH is small in the absence of other growth factors, although it is greatly enhanced by the presence of insulin or IGF-I at physiological concentrations (Kimura et al. 2001). Thus, the synergistic response of TSH+insulin/IGF-I on GRK2 expression parallels hormone effects on thyroid cell proliferation, suggesting a role for GRK2 in the growth of thyroid cancer. Here, we show that GRK2 overexpression in two different human thyroid cancer cell lines significantly attenuates serum-induced cell proliferation. This unexpected finding indicates that GRK2 interacts with receptors or proteins that have an important mitogenic function in thyroid cells. TSH-stimulated cAMP synthesis as well as lysophosphatidic acid-stimulated proliferative response (Iacovelli et al. 1999, 2002) was negatively regulated by GRK 2 in rat thyroid cells. As the cAMP cascade is involved in the control of human thyroid cell proliferation in vivo, it is tempting to speculate that in DTC, GRK2 would attenuate cAMP-dependent TSH signaling. However, FTC-238 and BRA-2 are poorly differentiated thyroid cancer cell lines where the TSH-Gs-cAMP system is not functional (Demeure et al. 1997), suggesting in these cells a GRK2 effect independent of TSH signaling.

It is usual to correlate an increased protein expression in cancers with their aggressiveness or their growth; however, our study demonstrates an inverse concept whereby the cell appears to use a physiological mechanism (GRK2 expression) to fight against cancer. Several recent findings have shown that GRK2 interacts with and phosphorylates proteins other than the GPCRs, broadening the variety of its cellular functions (Metaye et al. 2005). Thus, several targets for GRK2 have been discovered such as the platelet-derived growth factor receptor$\beta$ (PDGFR- $\beta$ ), the protein kinase Akt and the mitogenactivated protein kinase kinase (MEK), with a potential role in cell growth attenuation. Seryl phosphorylation of the PDGFR- $\beta$ by GRK2 increased receptor desensitization and diminished phosphoinositide hydrolysis, Akt activation and tyrosyl phosphorylation of the receptor itself (Hildreth et al. 2004). Furthermore, GRK2 overexpression reduced smooth muscle cells proliferation in vitro in response to endothelin-1 or PDGF and in vivo by studying neointimal hyperplasia in rabbit vein grafts (Peppel et al. 2002). On the other hand, a physical interaction of Akt with GRK2 was found in injured liver sinusoidal endothelial cells, inhibiting Akt activity (Liu et al. 2005). As Akt is a key mediator of several tyrosine kinase receptors, leading to cell survival or antiapoptosis (Shinohara et al. 2007), a link between Akt and GRK2 might exist in thyroid to reduce excessive growth of cancer. Finally, the GRK2 overexpression produced a significant attenuation of the extracellular signal-regulated kinase (ERK) response to the chemokine CC motif ligand 2 (CCL-2; Jiménez-Sainz et al. 2006) or to angiotensin II (Kim et al. 2005), involving a possible GRK2-MEK interaction or an arrestin-mediated system respectively. Given the role of MAPKs and chemokines in mitogenesis and motility of thyroid cancer cells, the regulation of these signaling cascades by GRK2 might represent fields of future research to better understand human thyroid cancer progression.

In summary, the present study showed an increased expression of GRK2 in non-medullary thyroid cancers using immunohistochemistry, western blotting and enzymatic activity measurement. Thyroid mitogenic factors, such as TSH or TSH + insulin/IGF-I, induced GRK2 accumulation in normal human thyroid cell culture. The contribution of GRK2 to attenuate cell growth revealed a new role for this kinase in the control of thyroid cancer progression. However, the mechanism by which GRK2 acts and the role of this kinase in human cancers other than thyroid remain to be explored.

\section{Declaration of Interest}

The authors declare that there is no conflict of interest that would prejudice the impartiality of this scientific work.

\section{Funding}

This work was supported by a grant from La Ligue contre le Cancer, Comité de la Vienne.

\section{Acknowledgements}

We thank Dr N Bennett (Laboratoire de Biophysique Moléculaire et Cellulaire, CNRS/CEA, Grenoble, France) 
for the generous gift of rod outer segment membranes. We are also grateful to B Aubouin and N Met for their technical assistances and to Prof D Sarrouilhe for his valuable discussion of the manuscript.

\section{References}

Bennett N \& Sitaramayya A 1988 Inactivation of photoexcited rhodopsin in retinal rods: the roles of rhodopsin kinase and $48-\mathrm{kDa}$ protein (arrestin). Biochemistry 27 1710-1715.

De Blasi A, Parruti G \& Sallese M 1995 Regulation of G protein-coupled receptor kinase subtypes in activated $\mathrm{T}$ lymphocytes: selective increase of $\beta$-adrenergic receptor kinase 1 and 2. Journal of Clinical Investigation 95 203-210.

Bradford MM 1976 A rapid and sensitive method for the quantitation of microgram quantities of protein utilizing the principle of protein-dye binding. Analytical Biochemistry 72 248-254.

DeLellis R, Lloyd RV, Heitz PU \& Eng C 2004 Tumours of the thyroid and parathyroid. In WHO classification of tumours. Pathology and genetics of tumours of endocrine organs, pp 49-103. Lyon: IARC Press.

Demeure MJ, Damsky CH, Elfman F, Goretzki PE, Wong MG \& Clark OH 1992 Invasion by cultured human follicular thyroid cancer correlates with increased beta 1 integrins and production of proteases. World Journal of Surgery 16 770-776.

Demeure MJ, Doffek KM \& Wilson SD 1997 Defective thyrotropin receptor G-protein cyclic adenosine monophosphate signaling mechanism in the FTC human follicular thyroid cancer cell line. Surgery 122 1195-1202.

Gagnon AW \& Kelly E 1997 Assay of G protein-coupled receptor kinase activity by rhodopsin phosphorylation. In Methods in Molecular Biology. Receptor Signal Transduction Protocols, Vol 83, pp 235-242. Ed RAJ Challiss. Totowa, NJ: Humana Press Inc.

Hildreth KL, Wu J-H, Barak LS, Exum ST, Kim LK, Peppel K \& Freedman NJ 2004 Phosphorylation of the platelet-derived growth factor receptor- $\beta$ by $G$ protein-coupled receptor kinase-2 reduces receptor signaling and interaction with the $\mathrm{Na}^{+} / \mathrm{H}^{+}$exchanger regulatory factor. Journal of Biological Chemistry 279 41775-41782.

Iaccarino G, Tomhave ED, Lefkowitz RJ \& Koch WJ 1998 Reciprocal in vivo regulation of myocardial $\mathrm{G}$ protein-coupled receptor kinase expression by $\beta$-adrenergic receptor stimulation and blockade. Circulation 98 1783-1789.

Iacovelli L, Franchetti R, Masini M \& De Blasi A 1996 GRK2 and $\beta$-arrestin1 as negative regulators of thyrotropin receptor-stimulated response. Molecular Endocrinology 10 1138-1146.

Iacovelli L, Franchetti R, Grisolia D \& De Blasi A 1999 Selective regulation of $G$ protein-coupled receptor-mediated signaling by $G$ protein-coupled receptor kinase 2 in FRTL- 5 cells: analysis of thyrotropin, $\boldsymbol{\alpha}_{1 \mathrm{~B}}$-adrenergic, and $\mathrm{A}_{1}$ adenosine receptor-mediated responses. Molecular Pharmacology $\mathbf{5 6}$ 316-324.

Iacovelli L, Capobianco L, D’Ancona GM, Picascia A \& De Blasi A 2002 Regulation of lysophosphatidic acid receptor-stimulated response by G-protein-coupled receptor kinase-2 and $\beta$-arrestin1 in FRTL-5 rat thyroid cells. Journal of Endocrinology 174 103-110.

Jiménez-Sainz MC, Murga C, Kavelaars A, Jurado-Pueyo M, Krakstad BF, Heijnen CJ, Mayor F, Jr \& Aragay AM 2006 G protein-coupled receptor kinase 2 negatively regulates chemokine signaling at a level downstream from G protein subunits. Molecular Biology of the Cell 17 25-31.

Kim J, Ahn S, Ren X-R, Whalen EJ, Reiter E, Wei H \& Lefkowitz RJ 2005 Functional antagonism of different $\mathrm{G}$ protein-coupled receptor kinases for $\beta$-arrestin-mediated angiotensin II receptor signaling. PNAS 102 $1442-1447$.

Kimura T, Van Keymeulen A, Golstein J, Fusco A, Dumont JE \& Roger PP 2001 Regulation of thyroid cell proliferation by TSH and other factors: a critical evaluation of in vitro models. Endocrine Reviews 22 631-656.

King DW, Steinmetz R, Wagoner HA, Hannon TS, Chen LY, Eugster EA \& Pescovitz OH 2003 Differential expression of GRK isoforms in nonmalignant and malignant human granulose cells. Endocrine 22 135-142.
Laemmli UK 1970 Cleavage of structural protein during the assembly of the head of bacteriophage T4. Nature 227 680-685.

Laugwitz KL, Allgeier A, Offermanns S, Spicher K, Van Sande J, Dumont JE \& Schultz G 1996 The human thyrotropin receptor: a heptahelical receptor capable of stimulating members of all four $\mathrm{G}$ protein families. PNAS $\mathbf{9 3}$ 116-120.

Leclere J, Bene M-C, Duprez A, Faure G, Thomas JL, Vignaud JM \& Burlet C 1984 Behaviour of thyroid tissue from patients with Graves' disease in nude mice. Journal of Clinical Endocrinology and Metabolism 59 175-177.

Liu S, Premont RT, Kontos CD, Zhu S \& Rockey DC 2005 A crucial role for GRK2 in regulation of endothelial cell nitric oxide synthase function in portal hypertension. Nature Medicine 11 952-958.

Lombardi MS, Kavelaars A, Schedlowski M, Bijlsma JWJ, Okihara KL, Van De Pol M, Ochsmann S, Pawlak C, Schmidt RE \& Heijnen CJ 1999 Decreased expression and activity of G-protein-coupled receptor kinases in peripheral blood mononuclear cells of patients with rheumatoid arthritis. FASEB Journal 13 715-725.

Metaye T, Menet E, Guilhot J \& Kraimps JL 2002 Expression and activity of G protein-coupled receptor kinases in differentiated thyroid carcinoma. Journal of Clinical Endocrinology and Metabolism 87 3279-3286.

Metaye T, Gibelin H, Perdrisot R \& Kraimps JL 2005 Pathophysiological roles of G-protein-coupled receptor kinases. Cellular Signalling $\mathbf{1 7}$ 917-928.

Moore CAC, Milano SK \& Benovic JL 2007 Regulation of receptor trafficking by GRKs and arrestins. Annual Review of Physiology 69 451-482.

Nagayama Y, Tanaka K, Hara T, Namba H, Yamashita S, Taniyama K \& Niwa M 1996a Involvement of G protein-coupled receptor kinase 5 in homologous desensitization of the thyrotropin receptor. Journal of Biological Chemistry 271 10143-10148.

Nagayama Y, Tanaka K, Namba H, Yamashita S \& Niwa M $1996 b$ Expression and regulation of $\mathrm{G}$ protein-coupled receptor kinase 5 and $\beta$-arrestin-1 in rat thyroid FRTL5 cells. Thyroid 6 627-631.

Parma J, Duprez L, Van Sande J, Cochaux P, Gervy C, Mockel J, Dumont J \& Vassart G 1993 Somatic mutations in the thyrotropin receptor gene cause hyperfunctioning thyroid adenomas. Nature 365 649-651.

Peppel K, Zhang L, Huynh TTT, Huang X, Jacobson A, Brian L, Exum ST, Hagen P-O \& Freedman NJ 2002 Overexpression of G protein-coupled receptor kinase-2 in smooth muscle cells reduces neointimal hyperplasia. Journal of Molecular and Cellular Cardiology 34 1399-1409.

Pitcher JA, Freedman NJ \& Lefkowitz RJ 1998 G protein-coupled receptor kinases. Annual Review of Biochemistry 67 653-692.

Prowatke I, Devens F, Benner A, Gröne EF, Mertens D, Gröne H-J, Lichter P \& Joos S 2007 Expression analysis of imbalanced genes in prostate carcinoma using tissue microarrays. British Journal of Cancer 96 82-88.

Pujol P, Daures J-P, Nsakala N, Baldet L, Bringer J \& Jaffiol C 1996 Degree of thyrotropin suppression as a prognostic determinant in differentiated thyroid cancer. Journal of Clinical Endocrinology and Metabolism $\mathbf{8 1}$ 4318-4323.

Ramos-Ruiz R, Penela P, Raymond B, Penn RB \& Mayor F, Jr 2000 Analysis of the human $\mathrm{G}$ protein-coupled receptor kinase 2 (GRK2) gene promoter; regulation by signal transduction systems in aortic smooth muscle cells. Circulation 101 2083-2089.

Ribas C, Penela P, Murga C, Salcedo A, García-Hoz C, Jurado-Pueyo M, Aymerich I \& Mayor F, Jr 2007 The G protein-coupled receptor kinase (GRK) interactome: role of GRKs in GPCR regulation and signaling. Biochimica et Biophysica Acta 1768 913-922.

Roger P, Taton M, Van Sande J \& Dumont JE 1988 Mitogenic effects of thyrotropin and adenosine $3^{\prime}, 5^{\prime}$-monophosphate in differentiated normal human thyroid cells in vitro. Journal of Clinical Endocrinology and Metabolism 66 1158-1165.

Russo D, Arturi F, Schlumberger M, Caillou B, Monier R, Filetti S \& Suarez HG 1995 Activating mutations of the TSH receptor in differentiated thyroid carcinomas. Oncogene 11 1907-1911.

Salcedo A, Mayor F, Jr \& Penela P 2006 Mdm2 is involved in the ubiquitination and degradation of G-protein-coupled receptor kinase 2. EMBO Journal 25 4752-4762. 
Van Sande J, Dequanter D, Lothaire P, Massart C, Dumont JE \& Erneux C 2006 Thyrotropin stimulates the generation of inositol 1,4,5-trisphosphate in human thyroid cells. Journal of Clinical Endocrinology and Metabolism 91 1099-1107.

Shepherd PR 2005 Mechanisms regulating phosphoinositide 3-kinase signaling in insulin-sensitive tissues. Acta Physiologica Scandinavica 183 3-12.

Shinohara M, Chung YJ, Saji M \& Ringel MD 2007 AKT in thyroid tumorigenesis and progression. Endocrinology 148 942-947.

Van Staveren WCG, Weiss Solís D, Delys L, Venet D, Cappello M, Andry G, Dumont JE, Libert F, Detours V \& Maenhaut C 2006 Gene expression in human thyrocytes and autonomous adenomas reveals suppression of negative feedbacks in tumorigenesis. PNAS 103 413-418.

Suarez HG, Du Villard JA, Caillou B, Schlumberger M, Parmentier C \& Monier R 1991 Gsp mutations in human thyroid tumours. Oncogene 6 677-679.
Theilade J, Lerche Hansen J, Haunsø S \& Sheikh SP 2002 Extracellular signalregulated kinases control expression of $\mathrm{G}$ protein-coupled receptor kinase 2 (GRK2). FEBS Letters $\mathbf{5 1 8}$ 195-199.

Vassart G \& Dumont JE 1992 The thyrotropin receptor and the regulation of thyrocyte function and growth. Endocrine Reviews 13 596-611.

Voigt C, Holzapfel HP, Meyer S \& Paschke R 2004 Increased expression of G-protein-coupled receptor kinases 3 and 4 in hyperfunctioning thyroid nodules. Journal of Endocrinology 182 173-182.

Voigt C, Holzapfel HP \& Paschke R 2005 Decreased expression of G-proteincoupled receptor kinases 2 in cold thyroid nodules. Experimental and Clinical Endocrinology and Diabetes 113 102-106.

Received in final form 17 April 2008

Accepted 23 April 2008

Made available online as an Accepted Preprint 23 April 2008 